\title{
Ovarian hyper stimulation syndrome: a case report
}

\section{Arti Patidar*, Balgopal Singh Bhati, Indra Bhati}

Department of Obstetrics and Gynaecology, S. N. Medical College, Jodhpur, Rajasthan, India

Received: 28 May 2016

Accepted: 17 June 2016

\section{*Correspondence:}

Dr. Arti Patidar,

E-mail: artipatidar8430@yahoo.com

Copyright: (c) the author(s), publisher and licensee Medip Academy. This is an open-access article distributed under the terms of the Creative Commons Attribution Non-Commercial License, which permits unrestricted non-commercial use, distribution, and reproduction in any medium, provided the original work is properly cited.

\section{ABSTRACT}

We present here a rare case ovarian hyper stimulation syndrome. In the case patient came with complain of abdominal pain, distension, nausea, vomiting with known case of secondary infertility.

Keywords: Infertility, Ovarian hyper stimulation syndrome, Polycystic ovaries

\section{INTRODUCTION}

Ovarian hyper stimulation syndrome (OHSS) is a potentially severe complication of induced ovulation and can results to significant morbidity and mortality. OHSS is cystic enlargement of the ovaries and a fluid shift from the intravascular space to the third space due to increased capillary permeability. Its occurrence is dependent on the administration of human chorionic gonadotropin (hCG) after an exaggerated ovarian response to gonadotropin stimulation. The syndrome is relatively common, occurring in up to $5 \%$ of women undergoing in vitro fertilization (IVF) or intrauterine insemination (IUI) procedures. $^{1}$

This potentially fatal condition is avoidable by the judicious use of gonadotropins and careful monitoring of stimulation regimens. Women who are at particular risk of developing the syndrome include those who have polycystic ovaries and those who are young (under 30 years). The pathophysiological hallmark of the ovarian hyper stimulation syndrome is a sudden increase of vascular permeability which results in the development of a massive extravascular exudate. Loss of fluid into the third space causes a profound fall in intravascular volume, haemoconcentration and suppression of urine formation. Loss of protein into the third space causes a fall in plasma oncotic pressure which results in further loss of intravascular fluid. Secondary hyperaldosteronism occurs and may cause hyponatremia. Clinical manifestations of OHSS can be classified into three forms. In mild forms of OHSS the ovaries are enlarged, while in moderate forms there is additional accumulation of ascites with mild abdominal distension. Its severe form is characterized by haemoconcentration, thrombosis, oliguria, pleural effusion, rarely pericardial effusion, and respiratory distress. ${ }^{2}$ It can lead to life-threatening complications including thromboembolic events and even death.

\section{CASE REPORT}

A 31 year old female with five years of secondary infertility underwent ovulation induction at a private hospital, 13 days later she hospitalized in Umaid Hospital with complain of abdominal pain, distension, nausea, vomiting. On examination she was well, afebrile, pulse $88 / \mathrm{min}$., BP $110 / 70 \mathrm{mmHg}$, oxygen saturation $94 \%$ on room air, air entry was slightly decreased in right side. Her abdomen was soft but slightly distended, shifting dullness was present. The WBC count 10,400/cu.mm, Hct $36 \%$, renal function, liver function and electrolytes were normal. The abdominal ultrasound revealed bilaterally enlarged multi-cystic ovaries and mild ascites. 
Chest ultrasound show mild pleural effusion on right side.

Conservative treatment with albumin infusion followed by diuretics was given. Body weight, abdominal circumference, intake and outputs, laboratory studies and ultrasonography were monitored. Hematological and biochemical parameter remained normal. She improved; plural effusion and ascites disappeared gradually and completely.

\section{DISCUSSION}

Ovarian hyper stimulation syndrome (OHSS) is an iatrogenic, serious complication of controlled ovarian hyper stimulation, usually self-limited, but occasionally life threatening. Two important risk factors that can be identified before treatment starts, are

\section{The presence of polycystic ovaries}

Several studies have confirmed that patients most at risk are women with the characteristic appearance on ultrasound of polycystic ovaries, not necessarily the polycystic ovary syndrome. ${ }^{3}$ The polycystic appearance occurs in $20 \%-33 \%$ of normal women but approximately $40 \%$ of patients undergoing IVF, irrespective of the indication for treatment. ${ }^{4}$ Women with polycystic ovaries on ultrasound but without the clinical features of the syndrome have a typical poly-follicular response to stimulation with gonadotropins that is indistinguishable from that seen in the patients with the clinical features of the syndrome. These observations indicate the value of identifying polycystic ovaries before treatment starts so that the dose of gonadotropin for stimulation can be adjusted appropriately.

\section{The patient's age}

Most cases of ovarian hyper stimulation syndrome occur in younger women, consistent with the greater ovarian responsiveness in this group compared with older women. ${ }^{4,5}$ Low body weight has also been associated with an increased risk for OHSS, presumably because of increased bioavailability of gonadotropins.

Although the pathophysiology of this syndrome has not been completely elucidated, the underlying mechanism responsible for the clinical manifestations of OHSS appears to be an increase in capillary permeability of mesothelium surfaces. ${ }^{6}$ The syndrome represents an over expression of the normal ovulatory process described in the pregnancy. The mechanism underlying the clinical manifestation of OHSS involves an increased permeability of the ovarian capillaries and of the mesothelium vessels triggered by the release of vasoactive substances by the ovaries under HCG stimulation. Two prime movers in the development of OHSS appear to be activation of the ovarian renin- angiotensin system and release of vascular endothelial growth factor (VEGF) from the ovary. ${ }^{7}$

The follicle contains renin in an inactive form which is activated at mid-cycle (and by exposure of the ovary to hCG) and which then causes conversion of angiotensinogen to angiotensin-I. This ovarian reninangiotensin system is thought to be involved in the neovascularization which is so central a feature of the conversion of the avascular pre-ovulatory follicle into the richly vascularized corpus luteum. ${ }^{8}$

Vascular endothelial growth factor (VEGF) increases capillary permeability and is expressed in steroid genic and steroid-responsive cells, such as those involved in repair of endometrial vessels and implantation. ${ }^{9}$ Recent evidence argues for a critical role of several other mediators including various cytokines such as interleukin IL-1, IL-6, IL-8 and tumor necrosis factor. ${ }^{10}$

Funding: No funding sources

Conflict of interest: None declared

Ethical approval: Not required

\section{REFERENCES}

1. Neulen J, Yan Z, Raczek S, Weindel K, Keck C, Weich HA, et al. Human chorionic gonadotropindependent expression of vascular endothelial growth factor/vascular permeability factor in human granulosa cells: importance in ovarian hyper stimulation syndrome. J Clin Endocrinol Metab. 1995;80:1967-71.

2. Bergh PA, Navot D. Ovarian hyper-stimulation syndrome: a review of pathophysiology. J Assist Reprod Genet. 1992;9:429-38.

3. Balen AH. The pathogenesis of polycystic ovary syndrome: the enigma unravels. Lancet. 1999;354:966-7.

4. MacDougall MJ, Tan SL, Balen AH, Jacobs HS. A controlled study comparing patients with and without polycystic ovaries undergoing in-vitro fertilization. Human Reproduction. 1993;8:233-7.

5. Delvigne A, Rozenberg S. Epidemiology and prevention of ovarian hyper stimulation syndrome. Human Reprod Update. 2002;8:559-77.

6. Polishuk WZ, Schenker JG. Ovarian overstimulation syndrome. Fertil Steril. 1969;20:443-50.

7. Agrawal R, Tan SL, Wild S, Sladkevicius P, Engmann L, Payne N, et al. Serum vascular endothelial growth factor concentrations in in-vitro fertilization cycles predict the risk of ovarian hyperstimulation syndrome. Fertil Steril. 1999;71:287-93.

8. Fabregues F, Balasch J, Manau D, Jiménez W, Arroyo V, Creus M, et al. Haematocrit, leukocyte and platelet counts and the severity of ovarian hyperstimulation syndrome. Hum Reprod. 1998;13:2406-10. 
9. Agrawal R, Conway G, Sladkevicius P, Tan SL, Engmann L, Payne N, et al. Serum vascular endothelial growth factor and doppler flow velocities in in vitro fertilization: relevance to ovarian hyperstimulation syndrome and polycystic ovaries. Fertil Steril. 1998;70:651-8.

10. Elchalal U, Schenker JG. The pathophysiology of ovarian hyperstimulation syndrome- views and ideas. Hum Reprod. 1997;12:1129-37.

Cite this article as: Patidar A, Bhati BS, Bhati I. Ovarian hyper stimulation syndrome: a case report. Int J Reprod Contracept Obstet Gynecol 2016;5:2418-20. 